\title{
The unavoidable need for distributed cognition in teaching literacy
}

\begin{abstract}
Certain tasks are more likely to be solved by groups than by individuals, even when the individuals are highly skilled at aspects of the task. These are tasks such as filling out income tax forms or performing surgical operations, for which inputs from several individuals who have complementary domains of knowledge and skill are needed. I refer to such tasks as those that require 'distributed cognition', and argue that teaching children to read is a prime example of such a task. Teaching children to read requires distributed cognition because so much knowledge about language, about pedagogy, about child development, and about literacy development is needed to do it well. Expecting that individuals acquire all that knowledge in a relatively brief pre-service teacher education programme is unrealistic. I suggest that a model in which teachers work in teams, or in which novice teachers can call on experts for advice, would serve both students and teachers better. Such a model presupposes a career trajectory for teachers, in which greater experience and knowledge generates greater responsibility and higher status. We need to replace the apprenticeship of personal experience with professional learning communities that can nurture the development of every novice teacher. Teaching literacy also requires unlearning a long list of commonsense beliefs that are incorrect and that can disrupt optimal teaching. I suggest that, while stereotypes and group-based expectations are very difficult to eliminate, behaviours based on those beliefs can be changed - and are more likely to be modified if work is undertaken collaboratively. Finally, distributed cognition is needed to compensate for the many difficult conditions under which teaching goes on. Overlarge classes, inadequate materials, poorly designed curricula, unsupportive school leaders, and many other challenges are faced regularly by teachers. Teachers should not be in the position of facing these challenges alone. In this article, I sketch out the kinds of knowledge that are required in teaching literacy, the kinds of widespread and common sense beliefs that need to be overcome in order to serve all children well, and the challenges to effective individual functioning that distributed cognition can help us address.
\end{abstract}

Keywords: reading, literacy, diversity, teacher preparation, teacher expertise

Catherine E. Snow, Harvard Graduate School of Education.

E-mail:snowcat249@gmail.com

South African Journal of Childhood Education | 2011 1(2): 1-10 | ISSN: $2223-7674$ |๑UJ
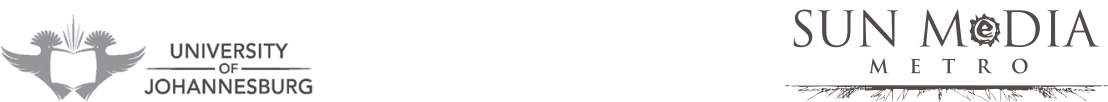
There is considerable evidence from studies of business administration and institutional leadership that certain tasks are more likely to be solved by groups than by individuals, even when the individuals are highly skilled at aspects of the task. These are tasks for which 'distributed cognition' is necessary - inputs from several individuals who have complementary domains of knowledge and skill. Everyday examples of distributed cognition include filling out one's tax returns, a task for which the taxpayer has one crucial component of the information needed (records of income, of business expenses, of outlays of various sorts) and the tax accountant has other components (which expenses are deductible, what is the most favourable way to calculate them, where to put the information onto the tax form). Another example of distributed cognition might be finding one's mislaid keys. There is no expert in this scenario - or rather the only expert (the person who mislaid the keys) is unable to deploy his expertise. How does someone else help in this circumstance? Typically by offering guiding questions or mechanisms, e.g. "When did you last see them? Did you check your overcoat pocket? Try retracing your steps." Here, distributed cognition joins the control of processing of the interlocutor with the covert knowledge of the key-owner to solve the problem. Many processes in daily life reveal the value of distributed cognition - comprehending difficult texts, deciding how to organise a pantry, plotting a route to a destination, and so on. In this essay, I argue that distributed cognition offers a solution to many problems in the field of teaching, particularly though not exclusively the teaching of reading. I also acknowledge that optimal use of distributed cognition will require changes in teacher preparation, teacher support, and the organisation of schools.

Why do I argue that distributed cognition is particularly relevant to teaching literacy? Teaching children to read is, in short, extremely difficult - in part because it requires access to a very large amount of knowledge about language, about reading, and about teaching practices and procedures. In addition, teaching literacy requires unlearning a long list of commonsense beliefs that are incorrect and that can disrupt optimal teaching. Finally, distributed cognition is needed to compensate for the many difficult conditions under which teaching goes on. In this article, I sketch out the kinds of knowledge that are required in teaching literacy, the kinds of beliefs that need to be overcome, and the challenges to effective individual functioning that distributed cognition can help us address.

\section{So much to teach}

Various documents produced over the last twenty years or so have specified the complexity of learning to read, and thus the many different points at which children might encounter difficulty. Some of these documents have produced lists of opportunities children need if they are to learn to read. For example, Preventing Reading Difficulties in Young Children, a USA National Research Council report (Snow, Burns \& Griffin, 1998) identified five opportunities to learn to which every child should have access:

- $\quad$ To become familiar with the forms and uses of written language; 
- To develop the language and meta-cognitive skills required for reading comprehension success at every point in literacy development;

- $\quad$ To grasp how the words of the language are structured and are represented in print by the letters of the alphabet and then practice those relationships to a point of automaticity;

- To become enthusiastic about learning to read and write; and

- If at risk of reading failure, to be noticed early and to be offered enriched experiences and intensified instruction in school.

In a subsequent volume, a subset of the committee that produced Preventing Reading Difficulties tried to extrapolate from these five child opportunities to formulate five desirable teacher opportunities to learn. That subsequent report, called Preparing Our Teachers (Strickland, Snow, Griffin, Burns, \& McNamara, 2002) similarly addressed five topics, but now by outlining what pre-service and in-service teachers should be learning in order to ensure that their students have access to the five opportunities listed above. The five chapters of Preparing Our Teachers, each of which addresses learning to support one of the opportunities, were entitled:

- $\quad$ From shopping lists to poetry: forms and function of written language

- Making meaning: language development and comprehension

- $\quad$ Sounds, letters, and words: How print works

- Moving to success: Motivating children to read

- Anticipating challenges: Assessment, prevention, and intervention

Of course, these lists only hint at the many specific capacities that primary grade teachers might be expected to have. The report of the USA National Reading Panel (NICHD, 2000) identified five pedagogical practices that should be part of a comprehensive reading instructional programme - thus implying that teachers also need to control specific curricular and pedagogical approaches associated with effective instruction in phonological awareness, systematic phonics, fluency, vocabulary, and comprehension. And of course we must not neglect the many other skills that are expected of primary teachers, which include at least establishing classroom routines, setting up the classroom as a productive learning space, maintaining discipline, learning about the students' home experiences, teaching math, teaching science, and teaching social studies.

\section{Back to distributed cognition}

So what does this lengthy inventory of the knowledge requirements for primary teachers have to do with distributed cognition? I would argue that it constitutes a challenge to the traditional model of teacher education. If we take seriously that teachers need to have the full range of knowledge and skills suggested above, then we certainly need to recruit only the most gifted students to teacher preparation programs, and we need to extend the preparation programme beyond the current 
relatively brief models to something that resembles the multi-requirement, multi-year preparation programmes for medicine or engineering.

Alternately, perhaps we should rethink the model of leaving an autonomous teacher alone in a classroom 'doing it all' for 20-50 children. It is impractical to expect every newly minted teacher education graduate to know everything s/he will need to implement in the classroom. We might nonetheless expect that full range of knowledge to exist in the group of teachers in a school. If schools operated with the default that teachers helped one another, that those with less experience could call on their senior colleagues for ideas and support, that observing successful teachers' practice was a normal activity, then the limitations of an individual's knowledge have fewer consequences for children.

Current policies (vide the National Reading Panel Report recommendations) also tend to assume that doing one set of things will work for all children. While that approach may simplify the teaching task, it does not necessary simplify or optimise students' learning. Some children may need much more focus on code instruction whereas others pick up letter-sound relationships quickly but need lots of focus on language skills. Skilled teachers identify these differentiated needs and adjust their instruction accordingly; less skilled teachers benefit from guidance to help them interpret student performance and select instructional activities accordingly (Connor, 2011). While it is key that learners have access to the full array of opportunities identified above, that does not imply that every student needs equal amounts of every opportunity.

It also does not imply that a single teacher must offer the full array of opportunities. Support for language and content knowledge development can come from a pull-in science teacher as well as from the literacy teacher. Motivation to read can come from experiences with a librarian or a parent volunteer in the classroom, as well as from the literacy teacher. The primary teacher may need a team to provide the full array of opportunities, in the right amounts, to all the students. Embedding the team idea, which is essentially an exploitation of distributed cognition, into educational practice would require updating our models for teacher action and teacher responsibility; as a benefit, the knowledge for teaching reading becomes accessible without requiring that every individual possess it all.

\section{Teacher knowledge about language}

In addition to the knowledge about literacy referred to above, it has been argued that teachers need extensive knowledge about language as a social and a technical system - how it develops (see Resnick \& Snow, 2008) and how it relates to reading comprehension (RAND Reading Study Group, 2002, Sweet \& Snow, 2003). In a 2002 volume entitled What Teachers Need to Know About Language (Adger, Snow \& Christian, eds.), Lily Wong Fillmore and I argued that there was a very long list of questions regarding language as a linguistic system that teachers should be able to 
answer. Examples of those questions include the following; many more are included in our chapter:

- What are the basic units of language?

- What's regular and what isn't? How do forms relate to each other?

- How is the lexicon acquired and structured?

- What is academic English?

- Why has the acquisition of English by non-English-speaking children not been more universally successful?

- Why is English spelling so complicated?

- Why do students have trouble with structuring narrative and expository writing?

- How should one judge the quality and correctness of a piece of writing?

- What makes a sentence or a text easy or difficult to understand?

With great idealism, we suggested in our 2002 chapter that teacher candidates should take a long list of courses or course segments to ensure that they acquire the knowledge required to answer these questions. We recommended - recognising at the time that this was an overoptimistic list - that teacher education programmes should offer the following courses: Linguistics, Language and Cultural Diversity, Sociolinguistics for Educators in a Linguistically Diverse Society, Language Development, Second Language Learning and Teaching, The Language of Academic Discourse, and Text Analysis and Language Understanding in Educational Settings. These seven courses represent, of course, almost a year's worth of study all on their own, and an amount unlikely to be made available in the average teacher education program. Conceding that teacher education programs are unlikely to be able to fit in all those courses and topics, and recognising that even if they did the candidates would vary in their probability of learning them all, we are faced again with a seemingly insurmountable obstacle. So what do we do if we think it is crucial that making instructional decisions requires having access to this knowledge? Once again, distributed cognition offers a solution; if teachers operated in teams and the knowledge was available within the team, then it would not be necessary that every individual possessed it.

\section{Knowledge to support the teaching of reading}

In 2003 The National Academy of Education appointed a committee to craft a set of recommendations about teacher education (Darling-Hammond \& Bransford, 2005). Because it was felt that there was a particularly strong basis in research findings to specify the knowledge base for the teaching of reading, a second committee focused on the preparation of teachers to teach reading was formed. Members of the reading subcommittee included: Richard Anderson, Joan Baratz-Snowden, M. Susan Burns, 
Peg Griffin, Claude Goldenberg, Louisa Moats, Annemarie Sullivan Palinscar, P. David Pearson, Catherine Snow (Chair), and Pam LePage (coordinator).

Both the committees started with two basic goals: The need for teacher education programmes to challenge the apprenticeship of personal experience, and their need to identify what future teachers must unlearn as well as what they must learn. The apprenticeship of personal experience, on which many teachers rely, is a very conservative force in educational practice. It means that even teachers who are exposed in their preservice programme to novel and progressive practices are unlikely to implement those innovations in their own classrooms.

The list of commonsense beliefs to unlearn represents a second huge challenge to teacher educators. These are beliefs that we all hold, but that can be particularly troublesome in classroom settings. These beliefs operate typically outside of consciousness, and yet influence interactions with students and assessments of their capabilities in highly consequential ways.

In Knowledge to Support the Teaching of Reading (Snow, Burns \& Griffin, 2005), we identified a long list of myths that influence our thinking about English Language Learners (ELLS), about speakers of nonstandard dialects, about children living in poverty, and about other groups that are seen as educationally challenging. I provide just a few examples of each here.

Among the myths held with regard to ELLs is the presumption that the native language of second language learners is secure, that exposure to two languages can confuse a child, that children who converse well in English should have adequate command of the language for school tasks, that young children will acquire English more rapidly than older children, and that learning to read in a second language is just like learning to read in a first language. None of these is true, or at least universally and simply true, and exploring the realities that counter these myths is a highly valuable component of any teacher education programme.

Speakers of nonstandard dialects, in particular of African-American Vernacular English, also elicit a long list of reactions based on myths, such as the following: nonstandard dialects are deficient forms of speech that oversimplify Standard English; the use of nonstandard forms is inconsistent with use of standard forms; phonological features of nonstandard dialects contribute to children's difficulty with learning sound-symbol correspondence; children need to acquire standard English before they can profit from reading instruction; and the use of a nonstandard dialect interferes with reading comprehension and fluency. Like the myths about ELLs, none of these claims is true in a simple or universal way, and some of them are never true. If teachers carry these beliefs into classrooms with them, they will not be able to support all their students' learning.

Children growing up in poverty likewise elicit a set of expectations from their teachers, expectations that research shows are unjustified. We often think that poverty is primarily a characteristic that operates via the family, rather than via the neighbourhood or local community. We may think that all children growing up poor 
are similarly disadvantaged, or that children who enter school with weak language and literacy skills will inevitably be poor readers. It is important to recognise that some schools serving poor children are highly effective, that the knowledge deficits of children from homes with poor literacy environments can be made up, and that children from disadvantaged homes and neighbourhoods need richer, more challenging instruction, not more focus on basic skills.

Again, what does any of this have to do with distributed cognition? These beliefs about second language speakers, about nonstandard dialect speakers, and about children from disadvantaged homes are extremely well-entrenched. They are not likely to change because we simply tell future teachers they are incorrect. We have good evidence in the USA that they do not change as the result of the courses in multicultural education designed to dislodge them.

In fact, it may be that these beliefs cannot be changed, but the actions based on them can be. Collaborative action is likely to be less influenced by this set of myths and misunderstandings than is individual action. Furthermore, new-shared understandings are more likely to become entrenched than are new individual understandings. Thus, breaking down classroom walls, giving teachers opportunities to work together and to observe and learn from one another is more likely to change deeply held beliefs than is yet another course or lecture or reading.

\section{Transcending the apprenticeship of personal experience}

Transcending the apprenticeship of personal experience will not happen without the introduction of an alternative model for teacher guidance. Snow, Burns and Griffin (2005) argued for the need to substitute for the current system a well-defined career trajectory for teachers, with carefully outlined standards of knowledge and competence for each stage of the trajectory. Progress through the stages is achieved through a process of progressive differentiation of function, associated with progressive assumption of greater responsibility; the process that characterises the career trajectories of medical doctors, chefs, and other professionals engaged in complicated practices.

In the first career stage, that of the preservice teacher candidate, it is clear that the primary form of knowledge accessible is declarative knowledge; the kind of knowledge it is possible to acquire by sitting in lectures and reading books. As teacher candidates start to participate in practice settings, they get access to procedural knowledge; knowledge of how to operate that is typically, in this early stage, highly specific to the original practice settings. Novice teachers entering their own classrooms should have developed stable procedural knowledge; knowledge they can rely on to guide their practice without recurrent help from a mentor teacher. That stable procedural knowledge is not, however, yet adaptive; it will serve the novice teacher in dealing with $60-80 \%$ of the students in her class, those who are within one standard deviation of the mean. Children who are very advanced, and those who are struggling mightily, are likely to challenge the novice teacher; for them s/he needs the help of an experienced, 
consulting teacher with a higher level of procedural knowledge, what we call 'adaptive' procedural knowledge. Finally, after some years of experience and greater experience with a wide variety of learners and settings, the experienced teacher turns into a master teacher, one who can analyse and reflect on her own adaptive procedural knowledge in such a way as to make it accessible to others. The master teacher can, thus, coach newer teachers, model lessons, provide professional development sessions, and in other ways make his/her knowledge accessible and usable to the wider group.

This model of a career trajectory for teachers implies that greater experience leads not just to more knowledge, but also to a different distribution of knowledge types. The total amount of knowledge a teacher has, of course, increases at successive career stages, but in addition the portion devoted to declarative knowledge (which dominates at the beginning) shrinks, leaving more room for procedural and, eventually, expert, reflective knowledge. The process of acquiring the mix of knowledge that characterises the experienced teacher requires recurrent cycles of a) new learning, b) putting new learning into practice, c) considering its effectiveness, and d) reflecting on the next steps. Only with the opportunity to participate in such cycles of learning and reflection can one's practice improve.

And what does this have to do with distributed cognition? The process of progressive differentiation of knowledge occurs optimally for teachers who

- function within a community of learners

- in which different individuals can be allowed to take on different roles

- in which development from novice to expert, with increasing responsibilities, is understood to be normal

- and in which the experts take responsibility for professionalising the novices.

Without access to the more developed understandings of the experienced teacher, we can hardly expect the novice to improve. Such access presupposes that classroom doors are open, which help can be requested, and that schools create opportunities for exchange and professional learning.

Any teacher who is frank about the conditions of education will note that those conditions are often not good. Resources are inadequate. Bad instructional programmes are often selected and imposed. Prescribed curricula may be inappropriate for some or most students, or inconsistent with teacher preferences. Students coming from poverty, from homes that offer little educational support, from violent neighbourhoods create behavioural and learning challenges. Administrators may be supportive and helpful, but often are uninsightful and obstructionist. There is much to compensate for in the actual conditions of teaching; it is unfair to ask teachers to take on their many challenges alone. Creating a culture in which distributed cognition is presupposed can be a way to help them persist and improve. 


\section{Back to the three models for distributed cognition}

I started this essay by offering up three specific situations, which demonstrate the value of distributed cognition:

- Filling out one's tax returns: there is an expert to rely on, and a structure that can be helpful though challenging;

- $\quad$ Finding one's keys: no one has the solution, but nonetheless joint problem-solving can be effective; and

- $\quad$ Fixing a meal: there are many experts, each with a special dish, who have to figure out how to work together.

While all of those show something about the affordances of the model, perhaps the most powerful and relevant model for distributed cognition is education itself. Teaching, I have argued, requires distributed cognition because it is so hard, and because there is so much to know that no one can be expected to know it all. But clearly learning is also a process of relying on others to guide and shape one's path. As such, it represents a willingness to enter into collaboration and to engage actively in the process of discovery; the very conditions that make distributed cognition possible.

\section{References}

Adger, C.T., Snow, C.E. \& Christian, D. (Eds.). (2002). What teachers need to know about language. Washington, DC, and McHenry, IL: Center for Applied Linguistics and Delta Systems Co., Inc.

Burns, M.S., Griffin, P. \& Snow, C.E. (Eds.). (1999). Starting out right: A guide to promoting children's reading success. Washington DC: National Academy Press.

Connor, C. (2011). Child characteristics-instruction interactions: Implications for students' literacy skills development in the early grades. In S. Neuman \& D. Dickinson (Eds.). Handbook of Early Literacy, (Vol. 3), p. 256-278. New York: Guilford.

Darling-Hammond, L. \& Bransford, J. (Eds.). (2005). Preparing teachers for a changing world. National Academy of Education Committee on Teacher Education. San Francisco: Jossey-Bass.

National Institute of Child Health and Human Development. (2000). Report of the National Reading Panel. Teaching children to read: An evidence-based assessment of the scientific research literature on reading and its implications for reading instruction (NIH Publication No. 00-4769). Washington, DC: USA Government Printing Office.

RAND Reading Study Group (Snow, C., Chair). (2002). Reading for understanding, toward an R\&D program in reading comprehension. Santa Monica: RAND.

Resnick, L. \& Snow, C.E. (2008). Speaking and listening for preschool through third grade (Rev. ed.). Newark, DL: International Reading Association. 
Snow, C.E., Burns, S. \& Griffin, P. (Eds.). (1998). Preventing reading difficulties in young children. Washington, DC: National Academy Press.

Snow, C.E., Griffin, P., Burns, M.S. \& the NAE Subcommittee on Teaching Reading. (2005). Knowledge to support the teaching of reading: Preparing teachers for a changing world. San Francisco: Jossey-Bass.

Strickland, D., Snow, C., Griffin, P., Burns, M.S. \& McNamara, P. (2002). Preparing our teachers: Opportunities for better reading instruction. Washington, DC: J. Henry Press.

Sweet, A. \& Snow, C.E. (Eds.). (2003). Rethinking reading comprehension. New York: The Guilford Press. 